\title{
Determination of Rational Technological Parameters of Obtaining the Product of Grain Processing
}

\author{
M.T. Shulbaeva \\ Candidate of Technical Sciences, Department \\ technological design of food production \\ Kemerovo State University \\ Kemerovo, Russia Federation \\ sh-m-t@yandex.ru

\section{V.N. Ivanets} \\ Doctor of Technical Sciences, Department \\ technological design of food production \\ Kemerovo State University \\ Kemerovo, Russia Federation \\ tppp@kemsu.ru
}

\author{
D.M. Borodulin \\ Doctor of Technical Sciences, Head of the Department \\ technological design of food production \\ Kemerovo State University \\ Kemerovo, Russia Federation \\ borodulin_dmitri@list.ru \\ E.A. Vagaitseva \\ Candidate of Technical Sciences, Department \\ technological design of food production \\ Kemerovo State University \\ Kemerovo, Russia Federation \\ vagaitseva@mail.ru
}

\author{
M.N. Potapova \\ Candidate of Technical Sciences, Department \\ technological design of food production \\ Kemerovo State University \\ Kemerovo, Russia Federation \\ potap-1962@list.ru
}

\begin{abstract}
This work reflects the perspective use of dry grain product of talgan, as a component of functional nutrition. There are two ways of producing this product. The new technology for obtaining talgan involves reducing the time of its preparation. A laboratory-research stand has been developed that allows the preparation and convective drying of the grain. Experimental studies have made it possible to establish rational parameters for the drying of grain crops using the new technology. Regression equations are obtained showing the relationship between the qualitative indices of the product and the technological parameters, namely the drying time and the equilibrium moisture content of the grain size and the temperature of the drying agent. The results of the analysis of the chemical composition of the product show that both grinding and temperature treatment have little effect on nutritional value. As a consequence, this determines the value of barley as a raw material in the creation of a promising functional ingredient - talgan by a new technology.
\end{abstract}

Keywords-functional nutrition, cereals, technological parameters, convective drying, drying curves

\section{INTRODUCTION}

Proper nutrition is an important condition for a healthy lifestyle. The main principle of proper nutrition is balanced diet. But due to the rapidly growing pace of life, modern people do not always have time to pay proper attention to their diets and therefore does not receive the necessary useful substances in sufficient quantities. In this regard, great interest is caused by enriched foods. A fortified food product is a functional food product obtained by adding one or more functional ingredients to traditional food products in an amount that ensures the prevention or replenishment of the nutritional deficiencies in the human body. For the first time, the term "functional product" was used in Japan, at the end of the 1980s, when a national nutrition improvement program was adopted [1-3].

One of the directions in the development of enriched food products is the use of additives from vegetable raw materials, in particular cereals. Cereals are the main source of vegetable protein and represent a real storehouse of energy, vitamins, minerals and fiber (dietary fiber). Dietary fibers stimulate the intestine, prevent the absorption of cholesterol into the blood and normalize the composition of the intestinal microflora [410].

An analysis of the state of the food industry in our country shows that, despite the increase in production, there remains 
high import dependence in most regions. This applies to specialized and functional products . Therefore, there is a need to support and develop its own production of food raw materials and food products.

One of the key aspects of food security is the volume of grain harvesting [11]. Russia has large areas and sufficient resources for the development of agriculture. According to the size of the crop areas, it is on the third place after the USA and China.

Wheat is the main grain crop of our country. It accounts for more than a third of the acreage cultivated for cereals, and the average yield is more than $24 \mathrm{cwt} / \mathrm{ha}$. The main volume of wheat harvest is in western and eastern Siberia, the Urals, the Volga region and the western part of Russia. Barley takes the second place in terms of production of cereals. It has good resistance to frost and drought, so it is grown almost throughout the country. The average yield is $23 \mathrm{cwt} / \mathrm{ha}$. The yields and availability of these crops make it possible to judge the expediency of using them as the main raw material in the production of food products.

Wheat and barley are rich in their food and energy composition. The average content of dietary fiber in the composition of these cereals by $58 \%-70 \%$ provides the daily allowance necessary for a person. Almost $20 \%$ of these crops provide the need for protein. It should be noted that our body absorbs protein of barley better than wheat protein. This is due to the presence of gluten (a complex protein), the content of which in wheat is 4 times higher.

In wheat and barley, there are many micro and macro elements. Wheat covers the daily rate in cobalt and manganese, provides $25 \%$ of the need for iron. Manganese stimulates the production of ascorbic acid and the synthesis of cholesterol, affects lipid metabolism and prevents excessive deposition of fat in the liver. Barley provides $35 \%$ of the daily norm in iron and $80 \%$ in manganese. Both cultures provide almost a $40 \%$ daily rate in zinc. Zinc provides rapid wound healing, promotes absorption of vitamin A and improves hair condition [12].

Wheat almost provides $50 \%$ of a daily rate in phosphorus, $27 \%$ in magnesium and $15 \%$ in calcium. Barley, in turn, covers the daily norm in silicon by $200 \%, 18 \%$ in calcium, $25 \%$ in magnesium and by $45 \%$ in phosphorus. Phosphorus is a tissueforming element and provides growth of bone and dental tissue. It also plays an important role in the formation of cells and the functioning of the kidneys. Magnesium helps to ensure the normal functioning of the nervous system and the full functioning of the muscles, and it plays an important role in the conversion of blood sugar to energy. Silicon is necessary for the formation of cartilaginous tissue, maintaining the elasticity and strength of blood vessels [13]. The amino acid composition of the grain contains 8 of the 8 essential amino acids. Irreplaceable amino acids are not produced in the body, but fall into it solely with food. These cultures provide $15-20 \%$ of the need for lysine, $10 \%$ of phenylalanine, which suppress pain, improve memory and help in the recovery of the skin, bones and muscles [14].
The use of these crops as functional additives will be economically viable and will increase the share of domestic products in this category.

Not so long ago a dry grain product called Talgan (in another transcription of talcane) appeared on the Russian market. Talgan (or talcane) is a traditional food of the peoples of Siberia and a number of other Turkic-speaking peoples. It is a fried and chopped grain. Talgan can be safely considered a universal product. It is not only an independent product, but also a functional additive. It was mixed with milk, sour cream, melted butter, or honey. They were stored in dry form in birch bark boxes, bags and wooden cylindrical vessels and used during hunting or on long trips. Another advantage of this product is a long shelf life (up to 12 months). The Talgan is a product, the use of which does not depend on the season of the year [15]. At present, the main production of Talgan is concentrated in Tatarstan, Bashkortostan, Khakassia and Altai. It is prepared according to classical technology from one or more types of cereals (wheat, barley, rye).

Currently, the talgan is used as a regular porridge boiled with boiling water, or used as an additional component to various dishes and products. So, for example, with its help it is possible to cook flour and confectionery products, pan meat products (cutlets), and also add to yoghurts, kefir, etc. Adding talgan to other dishes, we get not only the desired taste, but also a product with a balanced content of nutrients [16].

Due to 5 he presence of dietary fiber in the grain, talgan is easily digested and its main property is the improvement of the gastrointestinal tract. In addition, it removes toxic substances from the body, thereby purifying the body. Inclusion talgan in the diet helps to adjust nutrition, improve the skin, hair and nails. The harm of talgan can arise because of excessive use or because of intolerance of components.

If you talk about this product as a porridge, then to improve the taste in its composition, you can include various dried berries, fruits, nuts, etc., and to give the product a subtle notes of flavor in its composition you can include vanilla, cinnamon, nutmeg and other aromatic additives used in the food industry.

Due to the fact that talgan, as a product of mass consumption, has begun to be produced relatively recently, the process of its preparation on an industrial scale is poorly known and the search for new solutions related to its production technology is very relevant. Talgan, obtained by innovative technology, is intended for use in the recipe of new or traditional food products. With minimal processing and maximum preservation of valuable properties of the original grain, the talgan can be used in the recipe of a number of products that have therapeutic and preventive and functionaltechnological properties.

One of the key operations in the production of talgan is drying (or roasting) of grain, which affects not only the organoleptic characteristics, but also the biological and nutritional values of the product. Therefore, the purpose of this work is: to determine the rational technological parameters for obtaining the product "Talgan" of high quality. In accordance with the goal in the present work, the following main tasks were solved: 
1. To develop a laboratory and research stand for drying grain crops.

2. To investigate the kinetics of drying cereal crops and analyze the data obtained.

3. To conduct an analysis of the chemical composition of the finished product.

\section{OBJECTS AND METHODS OF RESEARCH}

The subject of the study is barley grain and wheat grain of the crop of 2016, grown in the territory of Tashtypsky district of the Republic of Khakassia.

For experimental studies, a laboratory research stand was developed, which is shown in Fig. 1. The grain was ground to a particle size of 1 to $5 \mathrm{~mm}$ in a batch mill. To carry out heat treatment of the crushed grain, a convective dryer was used, which allows the temperature of the drying agent to be regulated in the range of $50^{\circ} \mathrm{C}$ to $200^{\circ} \mathrm{C}$.

In the experiments, the temperature of the drying agent was varied from $150^{\circ} \mathrm{C}$ to $190^{\circ} \mathrm{C}$ in steps of $10^{\circ} \mathrm{C}$. Drying was subjected to a weight of 2 grams. Measurement of moisture content of grain grinding products was carried out in accordance with the procedure described in GOST 13586.52015 "Grain. Method for determination of humidity". Heat treatment of crushed grain samples was carried out to a constant mass (up to the achievement of equilibrium moisture), while the change in weight of the sample was recorded in the log of observations every minute.

The experiments were carried out in 3-fold replicates. The statistical processing was carried out with the built-in Microsoft Excel tools, as well as using the Statistika complex statistic analysis program, Industrial statistics, Nonlinear estimation and General regression models.

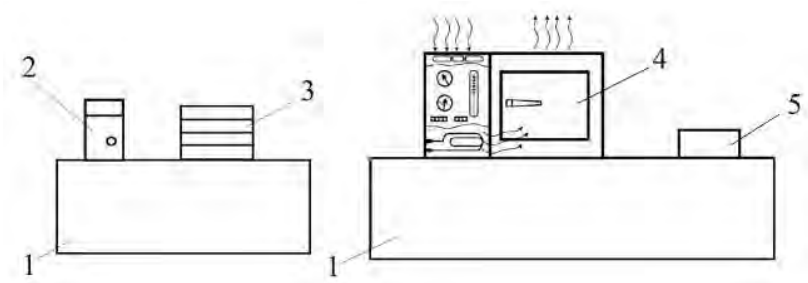

Fig. 1. Laboratory and research stand:

1 - table; 2 - mill; 3 - grain sieves; 4 - drying chamber; 5 - scales

The grain processing for obtaining talgan was carried out in the following sequence:

cleaning of grain from impurities;

grinding grain on a batch mill;

separation of the obtained crushed grain into fractions using grain sieves up to the size of $1 \mathrm{~mm} ; 2 \mathrm{~mm} ; 3 \mathrm{~mm} ; 4 \mathrm{~mm} ; 5 \mathrm{~mm}$;

preparation of samples of 2 grams;

heat treatment of grain grinding products in a convection dryer at temperatures of $150{ }^{\circ} \mathrm{C} ; 160^{\circ} \mathrm{C} ; 170^{\circ} \mathrm{C} ; 180^{\circ} \mathrm{C} ; 200^{\circ}$ with an exposure of 15 to 50 minutes; cooling the resulting talgan to a temperature not exceeding the ambient air temperature by more than $6-8^{\circ} \mathrm{C}$.

\section{RESULTS AND DISCUSSION}

The traditional technology for the production of a grain product, talgan, is shown in Fig. 2. The classic method of preparation is as follows: the whole grain with a shell is cleaned of impurities by means of a magnetic trap or a grain separator. Further, the purified mass is sent to the storage bin, from where it is fed to the fryer using a dispenser. The grain is dried for 10 to 12 minutes at $150{ }^{\circ} \mathrm{C}$. After roasting, the grains are discharged to a storage stabilizer, where they are cooled to room temperature. At the last stage, the fried grains are ground in a grain mill or hammer mill to particles with a size of $0.25-1$ $\mathrm{mm}$.

Disadvantage of this method is as the authors consider is long-term heat treatment at high temperature, resulting in increased energy consumption and partial destruction of biologically active substances, micro- and macronutrients of grains.

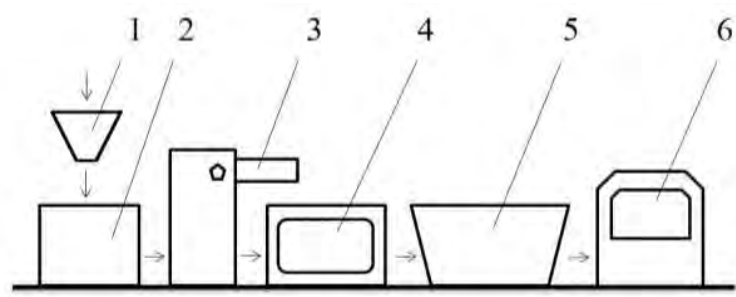

Fig. 2 Traditional scheme of preparation of grain product "Talgan": 1-metering device; 2 - grain cleaning separator; 3 - storage hopper; 4 - roaster; 5 - stabilizer-store; 6 - grain mill.

A new way of producing this product has been developed, which allows reducing the roasting time. The scheme of the innovative technological line for the production of the grain product "Talgan" is shown in Fig. 3.

The proposed innovative technology involves changing the order of the technological steps: first, grind the grain, and then conduct heat treatment. The hypothesis of the authors is that this approach will reduce the time of heat treatment while improving the quality and nutritional value of the resulting talgan because small particles require a more gentle influence of elevated temperatures, which will preserve the biologically active substances of grain and save labor and energy resources.

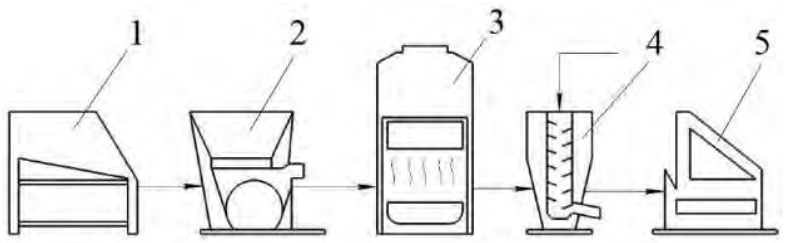

Fig. 3. Scheme of the innovative technological line for the production of grain products "Talgan":

1 - shale shaker with magnetic catchers; 2 - roller; 3 - roaster;

4 - mixer; 5 - filling machine. 
Deep processing of plant raw materials and the production on its basis of dry powdered ingredients is one of the most effective ways of compact transportation and organization of long-term storage of products, eliminating losses and reducing quality. In addition, the use of local raw materials for the production of new combined products will solve the actual issue of import substitution: not to depend on price fluctuations in the world market, work with local agricultural producers, produce demanded products.

Determination of rational technological parameters for convective drying of crushed wheat with particle sizes of $2 \mathrm{~mm}$ and $5 \mathrm{~mm}$ at $160^{\circ} \mathrm{C}, 180^{\circ} \mathrm{C}$ and $200^{\circ} \mathrm{C}$ is clearly shown in Fig. 4 and Fig. 5. Analysis of the curves in Fig. 4 shows that at the temperature of $160^{\circ} \mathrm{C}$, wheat reaches equilibrium moisture in 11 minutes. In this case, the grain acquires a light brown color with a golden hue of color, as well as a pleasant taste and aroma. At the temperature of $200^{\circ} \mathrm{C}$, wheat reaches equilibrium moisture content in 7 minutes, but at the same time it acquires a pronounced burning smell, which is unacceptable in Talgan. Thus, it was found that the optimum drying regime for the grain crushed to a particle size of $2 \mathrm{~mm}$ is $160-170^{\circ} \mathrm{C}$, the drying time is about 9 minutes.

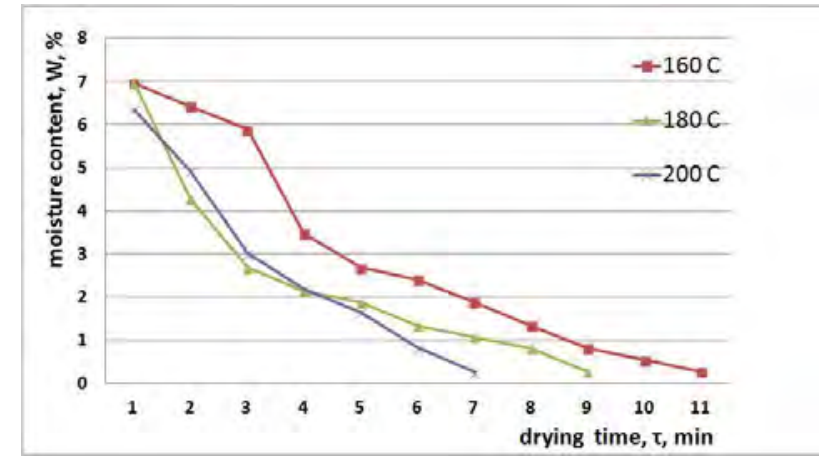

Fig. 4. Drying curves (grain size $2 \mathrm{~mm}$ )

Similar drying curves for the grain size of $5 \mathrm{~mm}$ are shown in Fig. 5.

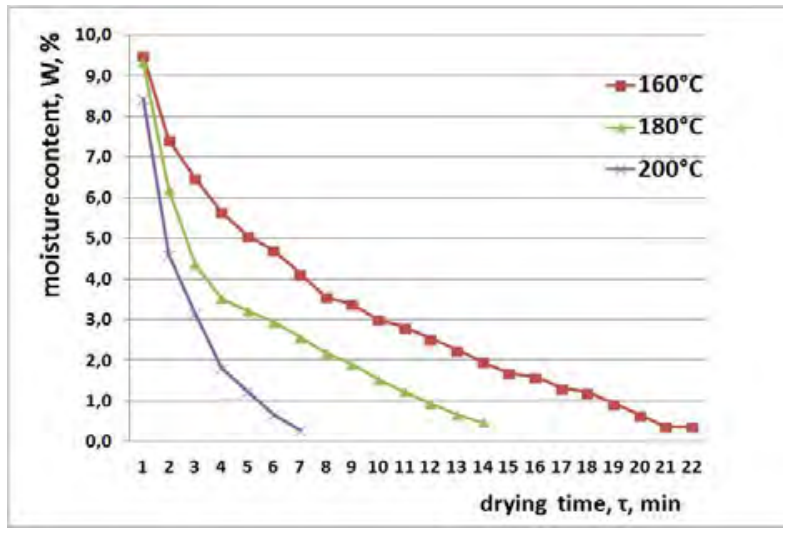

Fig. 5. Drying curves (particle size of grain $5 \mathrm{~mm}$ )
Since in this case the particles are larger, the equilibrium moisture content is reached for a little longer period of time than in the first case - from 10 to 27 minutes. However, the behavior and characteristics of the resulting talgan are similar to the previous version. Thus, it is confirmed that the optimum drying regime for the grain crushed to a particle size of $5 \mathrm{~mm}$ is also $160-170^{\circ} \mathrm{C}$, although achieving equilibrium moisture requires a longer period of time (about 15 minutes).

Based on the obtained experimental data on drying wheat, it was decided to expand the ranges of studies for a broader analysis. Therefore, the crushed barley, with an initial moisture content of 13.5-14.5\%, was dried at the drying agent temperature of $160^{\circ} \mathrm{C}$ to $190^{\circ} \mathrm{C}$, with the temperature step of $10^{\circ} \mathrm{C}$. In this case, the size of the crushed grains was $1 \mathrm{~mm}$ (and less), $2 \mathrm{~mm}, 3 \mathrm{~mm}, 4 \mathrm{~mm}$ and $5 \mathrm{~mm}$.

According to the obtained experimental data, the parameters of the current moisture in the material were determined. Based on the averaged data, drying curves of barley grains were constructed when exposed to drying agent with different temperatures. The drying curves of barley crushed to $2 \mathrm{~mm}$ are described using the equations (1)-(5).

For the temperature $150^{\circ} \mathrm{C}: W=-2.693 \ln (\tau)+7.2823$

For the temperature $160^{\circ} \mathrm{C}: W=-2.961 \ln (\tau)+7.4274$

For the temperature $170^{\circ} \mathrm{C}: W=-2.995 \ln (\tau)+6.9435$

For the temperature $180^{\circ} \mathrm{C}: W=-3.712 \ln (\tau)+8.2236$

For the temperature $190^{\circ} \mathrm{C}: W=-3.445 \ln (\tau)+8.359$

where $W$ - the moisture content of the crushed grain, $\%$, $\tau$ - duration of heat treatment (convection drying), min.

In the drying process, there is a tendency to reduce the drying time with increasing temperature, which is highly expected. It can also be noted that as the size of the crushed grains increases, the amount of moisture removed during the first minute of drying decreases. This is because of the fact that the smaller the material particles, the easier it is to remove moisture from them. After the first minute, the moisture is removed at moderate pace. For all samples, the drying agent temperature of $170^{\circ} \mathrm{C}$ is a rational drying parameter.

The regression model of the process is described by the equation (6):

$$
\begin{aligned}
& W_{P}=-7.9271+0.2203 \cdot d+0.0918 \cdot t- \\
& -0.0002 \cdot t \cdot d-0.0317 \cdot d^{2}-0.0003 \cdot t^{2}
\end{aligned}
$$

where $W p$ - the equilibrium moisture content, $\%$, $t$ - the temperature of the drying agent, ${ }^{\circ} \mathrm{C}$, $d$ - the average particle size of the crushed grain, $\mathrm{mm}$

It is established that the regression model is significant and adequate . Graphical interpretation of the model is shown in Fig. 6. The model was obtained using the tool "Regression of the mixture surface", intended specifically for the analysis of mixing experiments and the "Nonlinear models" module. The 
model can be used to predict the moisture content of the samples of crushed grain under the conditions of setting the experiment, the known dimensions of the particles and the drying temperature for convection heat treatment of the Talgan half-finished product.

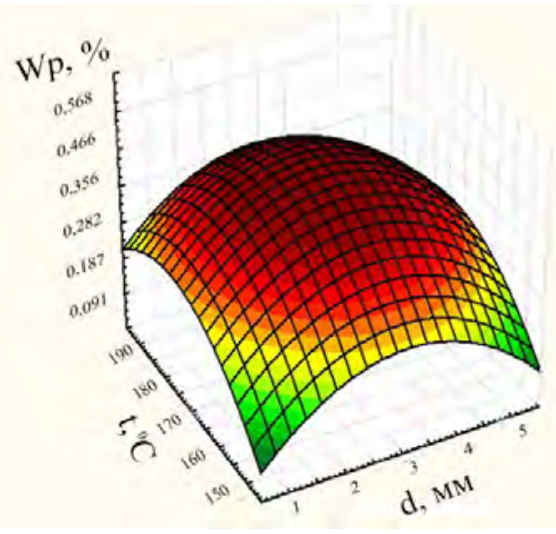

Fig. 6. Dependence of the equilibrium moisture content of the crushed grain of barley on the particle size and temperature of the drying agent

$W p$ - Equilibrium moisture \%,

$t$ - emperature of the drying agent, ${ }^{\circ} \mathrm{C}$,

$d$ - Size of crushed grain, mm

The rational technological parameters of convective drying of the crushed mixture of wheat and barley were determined. On the basis of theoretical and experimental studies, it was decided to conduct a series of experiments for a mixture of wheat and barley in a ratio of 50:50.

The parameters of the current moisture in the material are determined on the basis of which the drying curves of the mixture are constructed when exposed to a drying agent with different temperatures. The initial moisture content of the mixture ranged from $12-14 \%$. Analysis of drying curves for a mixture of wheat and barley ground to $1 \mathrm{~mm}$. at different temperatures showed that at the temperature of $150{ }^{\circ} \mathrm{C}$ the process time was 10 minutes, with the removal of $12 \%$ moisture. A change in the color and odor of the grain at the given temperature was not observed. At the temperature of 160 ${ }^{\circ} \mathrm{C}$, the drying time was reduced by 3 minutes. The loss of moisture, as in the previous case, was $12 \%$. At $170{ }^{\circ} \mathrm{C}$, the drying time was 6 minutes. The loss of moisture was $12.5 \%$. In the process of drying, the grain acquired golden color and pleasant, characteristic odor. Increasing the temperature to 180 ${ }^{\circ} \mathrm{C}-190^{\circ} \mathrm{C}$ led to a reduction in drying time to 5-4 minutes. Visual observations showed a noticeable darkening of the grain to dark brown color, 13.7 and $14.6 \%$ moisture being removed, respectively.

Thus, the best parameters of the drying process of the ground mixture, regardless of size, were obtained at the drying agent temperature of 160 and $1700^{\circ} \mathrm{C}$. As a result, the grains were exposed to short-term (in comparison with the traditional method), but sufficient heat treatment. The grains acquired golden brown color and pleasant characteristic odor.
In the next step the research of materials (wheat seed) and the product obtained by thermo-mechanical grain processing by the method described above (Talgan) was conducted. The data are presented in Table 1.

TABLE I. CHARACTERISTICS OF THE CHEMICAL COMPOSITION OF WHEAT TALGAN BEFORE AND AFTER THE TREATMENT (PARTICLE SIZE $2 \mathrm{MM}$ )

\begin{tabular}{|c|c|c|c|}
\hline \multirow{2}{*}{ Component } & \multirow{2}{*}{$\begin{array}{l}\text { Component } \\
\text { content } \\
\text { before } \\
\text { processing,\% }\end{array}$} & \multicolumn{2}{|c|}{$\begin{array}{l}\text { Component content } \\
\text { after processing, } \%\end{array}$} \\
\hline & & $\begin{array}{c}\text { for } \\
t=160^{\circ} \mathrm{C} \\
\end{array}$ & $\begin{array}{c}\text { for } \\
\mathrm{t}=\mathbf{2 0 0}\end{array}$ \\
\hline Water & $14.0 \pm 0.1$ & $7.00 \pm 0.1$ & $4.50 \pm 0.01$ \\
\hline Protein & $11.8 \pm 0.1$ & $9.8 \pm 0.1$ & $9.56 \pm 0.01$ \\
\hline Fat & $4.2 \pm 0.1$ & $1.30 \pm 0.1$ & $0.8 \pm 0.01$ \\
\hline $\begin{array}{l}\text { Carbohydrates: } \\
\text { starch } \\
\text { Sugar } \\
\text { Alimentary } \\
\text { fibers }\end{array}$ & $\begin{array}{c}64.4 \pm 0.1 \\
3.00 \pm 0.05\end{array}$ & $\begin{array}{l}65.20 \pm 0.1 \\
2.48 \pm 0.05\end{array}$ & $\begin{array}{l}65.35 \pm 0.1 \\
0.98 \pm 0.05 \\
1.72 \pm 0.05\end{array}$ \\
\hline $\begin{array}{l}\text { Mineral } \\
\text { substances }\end{array}$ & $3.50 \pm 0.05$ & $3.20 \pm 0.05$ & $3.40 \pm 0.05$ \\
\hline
\end{tabular}

As a result of this treatment, the chemical composition of wheat grains changes: the protein content is reduced from 2 to $2.24 \%$; the fat content is reduced by about 3 times. At the same time, the content of starch increases from 64.4 to $65.35 \%$, mineral substances also undergo changes. The decrease in the carbohydrate content is probably explained by the following. Wheat carbohydrates are mainly starch, which, as a result of heat treatment, can partially degrade to dextrins with better digestibility. The process of heat treatment of wheat plays an important role in the formation of taste, color and aroma, in particular due to the melanoid formation reaction and caramelization of sugars. Mono-sugars, represented by pentosans, and sugars can enter into a caramelization reaction to form furfural, formic and levulinic acids. Caramelization reaction leads to aldol condensation of carbonyl compounds, which are then converted to nitrogen-free brown polymers. As a result of heat treatment, inactivation of enzyme inhibitors also occurs, in particular, many proteinases, the digestibility of all food nutrients being increased.

Thus, during grinding and drying, the grain loses part of the protein, changes in the fat and carbohydrates fractions of the grain occur, and the moisture content decreases.

\section{CONCLUSION}

Based on the results of the studies, the perspective use of the grain product "Talgan" as a component of functional nutrition has been proved. A laboratory-research stand has been developed that allows preparation and convection drying of grain. Complex research has allowed establishing rational parameters of grain drying when obtaining the "Talgan" product using a new technology. This technology allows reducing the drying time by several times. The best indicators of the drying process of crushed grain crops:

- for wheat, it is rational to use the drying agent temperature of $160^{\circ} \mathrm{C}$ with the particle size of $2 \mathrm{~mm}$ and $5 \mathrm{~mm}$. The time spent on drying is 11 and 22 minutes, respectively. 
- for barley, it is rational to use the drying agent temperature of $160^{\circ} \mathrm{C}$ for particles with the size of $4 \mathrm{~mm}$ and $5 \mathrm{~mm}$. With this parameter, the time taken for drying is 22 and 20 minutes, and the equilibrium moisture content is $0.755 \%$ and $0.283 \%$. To dry particles of $1-3 \mathrm{~mm}$ size, it is rational to use the temperature of $170^{\circ} \mathrm{C}$. The time spent on drying is 6,10 and 11 minutes, after which the grain is evenly roasted, acquires golden color and pleasant aroma. The equilibrium humidity is $0.377,0.377$, and 0.187 , respectively.

- for mixture, regardless of the particle size, it is rational to use the temperature of the drying agent $170^{\circ} \mathrm{C}$. The average drying time is 13 minutes.

Regression equations are obtained showing the relationship between the qualitative indices of the product and the technological parameters, namely the drying time and the equilibrium moisture content of the grain size and the temperature of the drying agent. The results of the analysis of the chemical composition of the product show that grinding and temperature treatment has little effect on nutritional value. And as a consequence, this determines the value of grain as a raw material in the creation of the promising functional ingredient talgan by a new technology. The talgan obtained in this way has a fine-grained, crisp structure. It easily interacts with viscous and liquid components, evenly distributed in them, contributes to faster structure formation, and in fermented milk products such as yoghurt, kefir, fermented baked milk, talgan evenly mixes and stabilizes the mass. The use of talgan as a component increases the therapeutic and prophylactic properties.

\section{References}

[1] I. Kaya, "Motivation Factors of Consumers' Food Choice," Food and Nutrition Sciences, No 7, 2016, pp. 149-154.

[2] S. Bornkessel, S. Bröring, S.W.F.(Onno) Omta, and H. Trijp, "What determines ingredient awareness of consumers? A study on ten functional food ingredients," Food Quality and Preference, Vol. 32, Part C, March 2014, pp. 330-339.

[3] B. Goetzke, S. Nitzko, and A. Spiller, "Consumption of organic and functional food. A matter of well-being and health?", Appetite, Volume 77, June 2014, pp. 96-105.

[4] G. Aresa, L. Saldamandoa, A. Giméneza, A. Claretb, L.M. Cunhac, L. Guerrerob, A.P. Mourad, D. Oliveirae, R. Symoneauxf, and R. Delizag, "Consumers' associations with wellbeing in a food-related context: A cross-cultural study," Food Quality and Preference, vol. 40, Part B, March 2015, pp. 304-315.
[5] O. Musina, P. Putnik, M. Koubaa, F.J. Barba, R. Greiner, D. Granato, and Sh. Roohinejad, "Application of modern computer algebra systems in food formulations and development: A case study," Trends in Food Science \& Technology, Vol. 64, June 2017, pp. 48-59.

[6] M. Yannakoulia, N. Yiannakouris, L. Melistas, M.D. Kontogianni, I. Malagaris, and S. M. Christos, "A dietary pattern characterized by high consumption of whole-grain cereals and low-fat dairy products and low consumption of refined cereals is positively associated with plasma adiponectin levels in healthy women," Metabolism, Vol. 57, June 2008 pp. 824-830.

[7] D. Charalampopoulos, R. Wang, S.S Pandiella, and C. Webb, "Application of cereals and cereal components in functional foods: a review," International Journal of Food Microbiology, Vol. 79, No 1-2, 2012, pp. 131-141.

[8] Y. Spandiyarov, M. Nemerebayev, A. Borankulova, and B. Soltibaeva, "The generalized equation of creep talkan in conditions uniaxial compression in the closed volume," Mechanics and technologies, no 3(45), 2014, pp. 131-135.

[9] K.L. Konovalov, A.I. Loseva, M.T. Shulbaeva, and N.V. Pechenik, "Creation of qualitatively new products with the set properties," Food industry, no 5, 2010, pp. 26-29.

[10] A. Das, U. Raychaudhuri, and R. Chakraborty, "Cereal based functiona food of Indian subcontinent: a review," Food Science and Technology, Vol. 49, Iss. 6, December 2012, pp 665-672.

[11] V.N. Ivanova, S.N. Seryogin, and N.D. Avarian, "Production, Processing and Storage of Agricultural Products, Raw Materials and Food": Aims and Objectives, the Main Priorities of the Development," Food industry, no 1, 2017, pp. 8-12.

[12] Iu. Aprodu and Iu. Banu, "Milling, functional and thermo-mechanical properties of wheat, rye, triticale, barley and oat," Cereal Science, Vol. 77, September, 2017, pp. 42-48.

[13] P. Sullivan, J. O'Flaherty, N. Brunton, V.L. Gee, E. Arendt, and E. Gallagher, "Chemical composition and microstructure of milled barley fractions," European Food Research and Technology, Vol. 230, Iss. 4, February 2010, pp. 579-595.

[14] A. Drakos, G. Kyriakakis, V. Evageliou, St. Protonotariou, I. Mandala, and Ch. Ritzoulis, "Influence of jet milling and particle size on the composition, physicochemical and mechanical properties of barley and rye flours," Food Chemistry, Vol. 215, January 2017, pp. 326-332.

[15] K.L. Konovalov, O.N. Musina, S.M .Lupinskaya, M.T. Shulbaeva, and L.G. Shaykhutdinova, "Milk protein product with plant raw materials, adapted to the national traditions of Western Siberia food," Dairy industry, no 10, 2015, pp. 50-52

[16] N.E. Yaytseva, E.A. Savinkova, and O.Yu. Petrov, "Application of a talkan in technology of products from fowl," Topical issues of improvement of the production technology and processing of production of agriculture, No. 18, 2016, pp. 167-168. 